\title{
Production of Electricity from Rice Straw with different Pretreatment Methods Using a Sediment Microbial Fuel Cell
}

\author{
Tian-shun Song ${ }^{1,2,3,4}$, Shuai Hou ${ }^{1,3}$, Jiguang Zhang ${ }^{1,3}$, Haoqi Wang ${ }^{1,3}$, Jingjing Xie $^{1,2,3,4, *}$ \\ ${ }^{1}$ State Key Laboratory of Materials-Oriented Chemical Engineering, Nanjing Tech University, \\ Nanjing 211816, PR China \\ ${ }^{2}$ CAS Key Laboratory of Bio-based Materials, Qingdao Institute of Bioenergy and Bioprocess \\ Technology, Chinese Academy of Sciences, Qingdao 266101, China \\ ${ }^{3}$ College of Life Science and Pharmaceutical Engineering, Nanjing Tech University, Nanjing 211816, \\ PR China \\ ${ }^{4}$ Jiangsu National Synergetic Innovation Center for Advanced Materials (SICAM), Nanjing 211816, \\ PR China \\ *E-mail: xiej@njtech.edu.cn
}

doi: $10.20964 / 2018.01 .28$

Received: 7 September 2017 / Accepted: 31 October 2017 / Online Published: 1 December 2017

\begin{abstract}
The purpose of this study is to improve the performance of solid phase microbial fuel cells (SMFC) by pretreating straw with several reagents $\left(\mathrm{H}_{2} \mathrm{SO}_{4}, \mathrm{NaOH}\right.$ and $\left.\mathrm{H}_{2} \mathrm{O}_{2}\right)$. Electrochemical performance and straw properties were measured. The results show that when compared with the control group (untreated rice straw), the SMFC with rice straw after hydrogen peroxide pretreatment $\left(\mathrm{SMFC}-\mathrm{H}_{2} \mathrm{O}_{2}\right)$ and the SMFC with rice straw after sulfuric acid pretreatment $\left(\mathrm{SMFC}-\mathrm{H}_{2} \mathrm{SO}_{4}\right)$ lasted more than 6 to 8 days under high voltage (higher than $500 \mathrm{mV}$ ). Furthermore, an SMFC with rice straw after sodium hydroxide pretreatment ( $\mathrm{SMFC}-\mathrm{NaOH}$ ) can last more than 22 days under high voltage, which is almost twice the endurance of the control group. The maximum power density of the SMFC-NaOH was 140 $\mathrm{mW} / \mathrm{m}^{2}$ on day 50 , which was 3.6 times that of the control. Therefore the $\mathrm{NaOH}$ pretreatment worked in favor of rice straw biodegradation by anaerobic microorganisms and extended the sustained discharge time of the SMFC.
\end{abstract}

Keywords: Straw resource utilization; Electricity; Long discharge; Cellulose; Pretreatment

\section{FULL TEXT}

(C) 2018 The Authors. Published by ESG (www.electrochemsci.org). This article is an open access article distributed under the terms and conditions of the Creative Commons Attribution license (http://creativecommons.org/licenses/by/4.0/). 